\title{
States with Community Solar Policy Updates and Capacity Growth Potential
}

National Renewable Energy Laboratory

Emily Fekete

November 20, 2020 


\section{States with Potential to Expand Installed Capacity}

This section highlights states with promising community solar programs or policies, but not many interconnected projects 


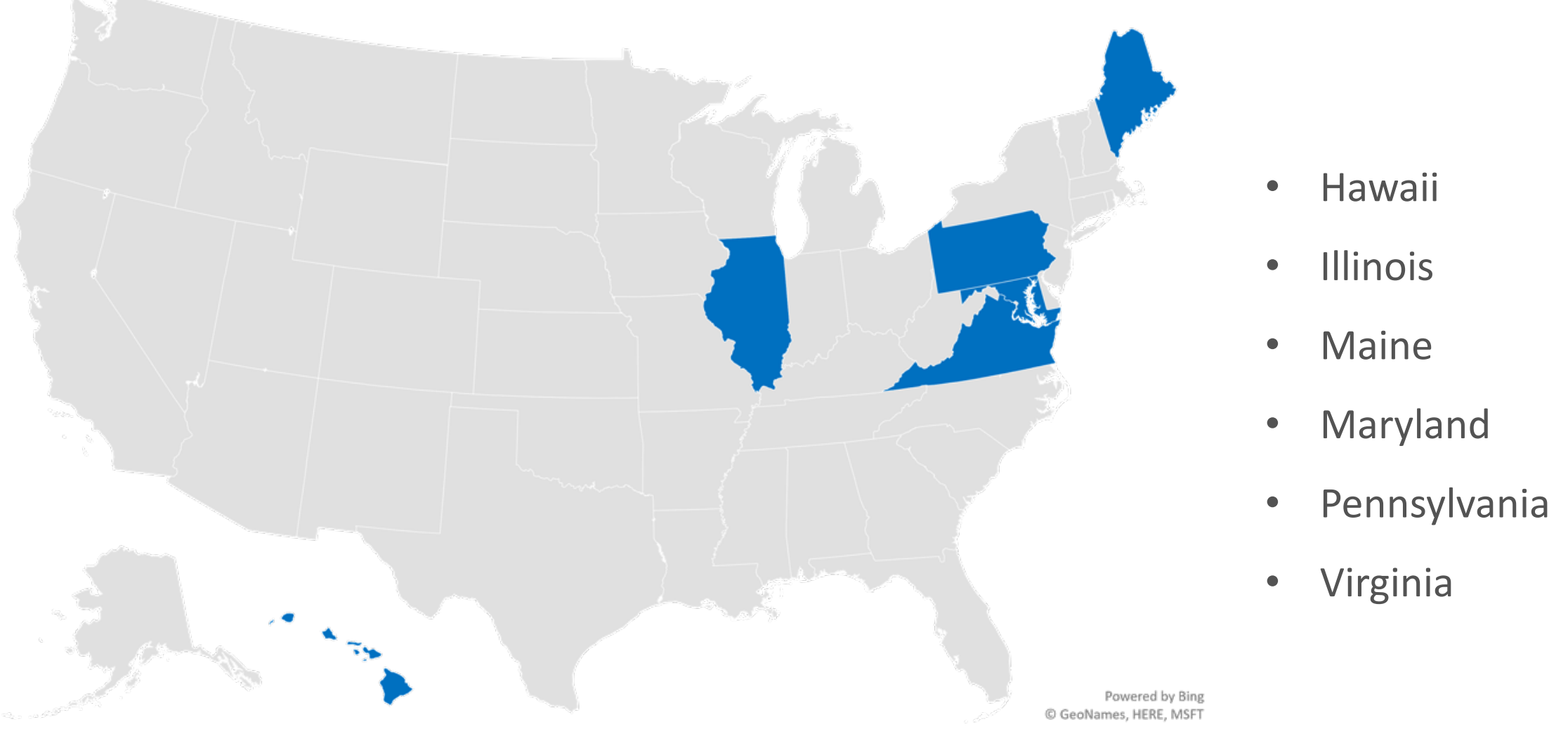

States with Expanding Community Solar Policies 


\section{Hawaii}

More Information on the Community- Based Renewable Energy expansion Here

For the most up to date information on Hawaiian Electric's Community-Based Renewable Energy Program Here

In April 2020, the Hawaii PUC approved a second phase for their Community-Based Solar program

- The first phase included $8 \mathrm{MW}$ of community solar

- The recently approved second phase will allow $235 \mathrm{MW}$ for new community solar projects

- Including both small-scale $(<250 \mathrm{~kW})$ and large-scale projects ( $\geq 250 \mathrm{~kW}$ )

- Focused on low-and-middle-income residential customers

- The PUC is recommending a pay-as-you-go or on-bill repayment options for customers who cannot make a large down-payment, and other financing options that will encourage broad participation 


\section{Illinois}

\section{Adjustable Block Program Community Solar \\ 200 Capacity Installed in Illinois (MWac)}

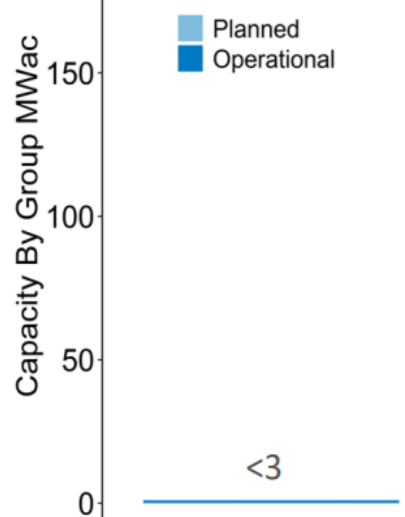

In Operation

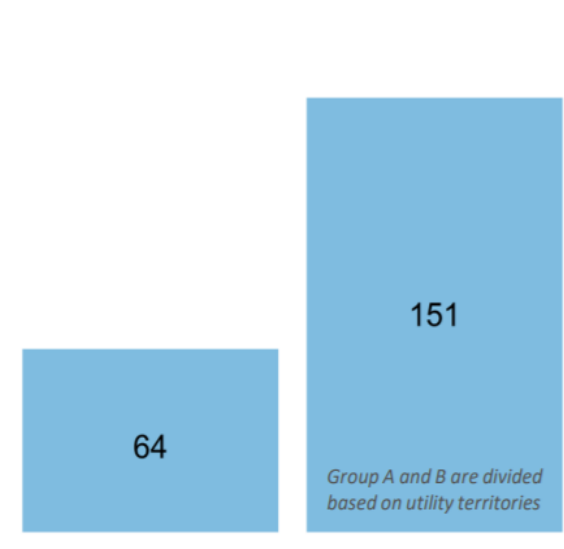

Planned-Group A Planned-Group B
Data Source: For community solar projects in operation: NREL/UMN Sharing the Sun Project List; for planned community solar: Illinois Power Agency Adjustable Block Program Lottery Results The planned status in this figure represents community solar projects accepted through the lottery The solid blue represents the cumulative nameplate capacity (MWac) for solar gardens in operation by 2019 in IL. The semitransparent blue represent the nameplate capacity (MWac) of planned solar gardens.

Illinois created its Solar for All program in December 2016, which includes incentives for low-income projects- however, very few of the accepted projects are in operation

- The lottery for projects to receive an incentive via the Illinois Power Agency's Adjustable Block Program accepted more than $200 \mathrm{MW}$ of community solar projects

- At the end of 2019 , only $3 \mathrm{MW}$ of community solar were in operation

Illinois is currently not in the top 10 community solar states by capacity, but likely will be after the majority of planned projects come into operation 


\section{Maryland}

Learn more about Maryland's community solar pilot program $\underline{\text { Here }}$

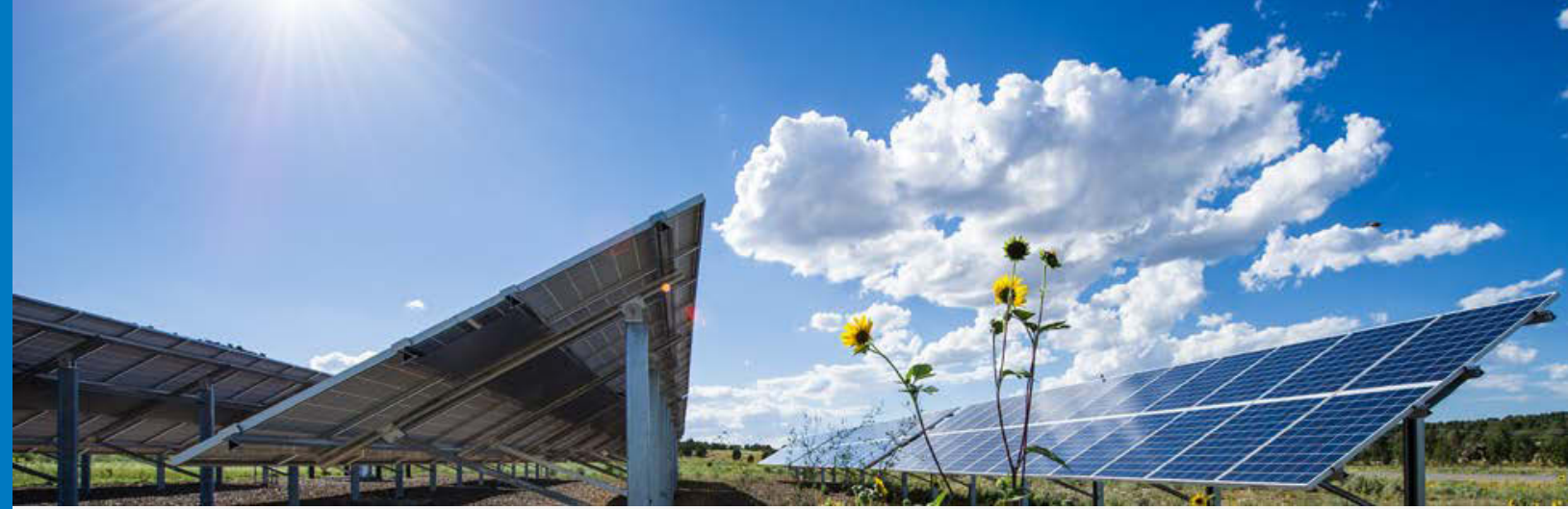

Maryland commenced its community solar pilot program in 2017

- The program has a cap at $418 \mathrm{MW}$, including a $125 \mathrm{MW}$ low-to-moderate income carve out

- Currently 2.34 MW of community solar are operational

- Utilities are still reviewing applications for projects

Maryland is also currently not in the top 10 community solar states by capacity, but will likely rise in ranking as more projects are accepted and become operational 


\section{Pennsylvania}

More information on $\underline{\mathrm{HB}} 531$

More information on $\underline{\mathrm{SB} 705}$

- Pennsylvania does not currently have a community solar program or implemented policies

- Two bills have been introduced-House Bill 531 and Senate Bill 705- with bi-partisan support to initiate a community solar program in the state

- The legislation would allow community solar projects, which are currently blocked by state utility laws

- Subscribers would receive a credit on their monthly bills for the energy produced

- Includes language to support low-income inclusion

- The bills are being promoted as a means of economic recovery for the state 
2019 Policies, Amendments, and Program Updates

This section highlights who updated their community solar policies or programs in 2019 


\section{Colorado}

\section{HB19-1003 Colorado Solar Gardens Modernization Act}

- 2019 Amendments to the Bill include:

- Increases the maximum size of a community solar garden (CSG) from 2 megawatts to 5 megawatts, with the option for the public utilities commission (PUC) to authorize construction of a CSG up to 10 megawatts beginning July 1, 2023

- Removes requirement that a CSG subscriber's identified physical location be in the same county as, or a county adjacent to, that of the CSG, but still requires it to be within the utility service territory 


\section{Massachusetts}

\section{Solar Massachusetts Renewable Target (SMART) Program}

- SMART Program Launched in late 2018

- 400 MW review occurred in 2019, after 400 MW of eligible Solar Tariff Generation Units were generated

- Expands the SMART program by $1600 \mathrm{MW}$

- Broadens the definition of a Low-Income Customer to expand the benefits of the Low-Income Community Shared Solar Adder

- Increases the Public Off-Taker Adder from $\$ 0.02 / \mathrm{kWh}$ to $\$ 0.04 / \mathrm{kWh}$

- Strengthens consumer protection standards

- Changes implemented in April \& May 2020 


\section{New Hampshire}

Senate Bill 165-Relative to net energy metering by low-moderate income (LMI) community solar projects

Details on the bill:

- Sets rate at which credits can be given to each LMI community solar project host and participating members

- Requires the Public Utilities Commission (PUC) to report on the costs and benefits of additional credit and the development of the market for LMI community solar projects

- Requires that the commission authorize at least 2 new LMI community solar projects each year in each utility's service territory beginning January 1, 2020

- No more than 15 percent of the projected load for each project can be attributable to non-residential end-user customers 


\section{New York}

\section{9-M-0463-Consolidated Billing for Distributed Energy}

\section{Resources}

- Details of the bill:

- Introducing consolidated billing for distributed energy resources

- Implements net crediting model

- Community distribution generation (CDG) savings rates for each project will be provided to members after the subscription charge is subtracted out

- Allows developers to collect the costs directly from the utility 


\section{Policies, Amendments, and Program Updates}

This section highlights who updated their community solar policies or programs in 2020 


\section{California}

\section{Building Energy Efficiency Standards}

- On 2/20/20 the California Energy Commission approved Sacramento Municipal Utility District's (SMUD) Neighborhood SolarShares Program

- The approved program allows community solar to substitute for the solar panels to be installed on all newly constructed homes as mandated by the 2019 Building Energy Efficiency Standards

- This is the first program to be approved by the Commission under the 2019 Energy Code and sets a precedent for other utilities and home builders to utilize community solar as an alternative to rooftop solar panels on newly constructed homes 


\section{Massachusetts: Pending Legislation}

Bill S. 2477/ Bill S. 2500: An Act setting next-generation climate policy

- Community Solar and LMI Components of the Bill:

- Any incentive program developed must include solar tariff generation units that primarily serve low-income customers, including low-income community solar tariff generation units

- An outreach program to educate and inform low-income customers and residents of LMI housing about the benefits and savings associated with participation in the solar incentive programs

- Current Status:

- With House Committee as of 8/6/2020 


\section{New Jersey}

New Jersey Board of Public Utilities (NJBPU) approved transition from the previous SREC to the Transition Renewable Energy Credit (TREC)

New Jersey transitioned away from Solar Renewable Energy Credits (SRECs) when $5.1 \%$ of electricity sold was sourced from solar, which occurred in May 2020

- The replacement for the SREC is the TREC, which was approved in late 2019, and will have a different value than the SREC

- Any project that has applied for SRECs after October 29,2018, but was not fully operational by the time the $5.1 \%$ threshold was met (May 2020) will be eligible for TRECS

- The value of TRECs was set in Early March 2020 by the Board of Public Utilities

- Fixed price of $\$ 152$ per TREC for 15 years determined by the type of solar installed

- This is different from the SRECs, which were a variable price determined by market supply vs. demand

- After 15 years of eligibility, projects may be eligible for a NJ Class I REC. 


\section{New York}

\section{Order Extending and Expanding Distributed Solar Incentives}

Details on petition:

- In November 2019, NYSERDA filed a petition with the Public Service Commission (PSC) seeking \$573 million in additional funds to Extend the NY-Sun program through 2025. The petition was granted May 14, 2020

- \$111 million of the approved funds will be used to replenish "Community Adder" incentives for community solar projects

- An additional adder will be funded for projects paired with storage, and those that provide resiliency or financial benefits to LMI customers and affordable housing

- \$135 million of additional funds planned for LMI customers, including no cost community solar to LMI households, in addition to MW Block incentives, and Community Adder incentives 


\section{Virginia}

\section{SB629: Distributed electric generation; community solar gardens}

- $\quad$ Amendments to the Bill include:

- Instructs State Corporation Commission (SCC) to initiate proceedings to establish a shared solar program for customers Dominion which allows customers to purchase electric power through a subscription in a shared solar facility and receive bill credits commensurate to their subscription

- Program must take affect by July 1,2023 , or once Dominion has implemented a new customer information platform

- SCC currently setting regulations for the program

- Projects capped at $5 \mathrm{MW}$, and program capped at $150 \mathrm{MW}$ with another $50 \mathrm{MW}$ pending

- Requires $40 \%$ capacity to be subscribed to by customers with subscriptions of 25 kilowatts or less (residential customers)

- Establishes standards for bill crediting

- Allows rollover to following month when bill credit is more than monthly bill

- 25-year agreements

- Utilities must provide a monthly report

- Creates a stakeholder working group including low-income community representatives and community solar providers to facilitate low-income customer and low-income service organization participation in the program 


\section{Virginia}

House Bill 572: Community solar development pilot program; low-income communities

- Requires of investor-owned utilities (IOUs), excluding Appalachian Power, to initiate a multi-family shared solar program

- The programs will allow eligible multi-family customers to purchase electric power through a subscription in a shared solar facility

- Each utility's program will be executed after a new customer information platform has been implemented, or by July 1, 2023, whichever is sooner

- The SCC is currently setting regulations for the program 


\section{Virginia}

House Bill 573: Community solar development pilot program; low-income communities

- Amends the existing 2017 community solar pilot program legislation:

- Requires utility controlled and operated community solar programs to select a community solar project within a low-income community for every project that is selected outside of a low-income community

- Each project selected in a low-income community must also be of equal or greater value to the project selected outside of a lowincome communities to ensure that projects both in and outside of low-income communities are equally funded 


\section{Thank You}

\section{www.nrel.gov}

NREL/PR-6A20-78174

This work was authored by the National Renewable Energy Laboratory, operated by Alliance for Sustainable Energy, LLC, for the U.S. Department of Energy (DOE) under Contract No. DE-AC36-08GO28308. Funding provided by the U.S. Department of Energy Office of Energy Efficiency and Renewable Energy Solar Energy Technologies Office. The views expressed in the article do not necessarily represent the views of the DOE or the U.S. Government. The U.S. Government retains and the publisher, by accepting the article for publication, acknowledges that the U.S. Government retains a nonexclusive, paid-up, irrevocable, worldwide license to publish or reproduce the published form of this work, or allow others to do so, for U.S. 